\title{
USE OF A BOVINE JUGULAR VEIN GRAFT WITH NATURAL VALVE FOR RIGHT VENTRICULAR OUTFLOW TRACT RECONSTRUCTION: A ONE-YEAR ANIMAL STUDY
}

Yukio Ichikawa, $\mathrm{MD}, \mathrm{PhD}$

Yasuharu Noishiki, MD, PhD

Takayuki Kosuge, MD, PhD

Kenji Yamamoto, MD, PhD

Jiro Kondo, $\mathrm{MD}, \mathrm{PhD}$

Akihiko Matsumoto, MD, $\mathrm{PhD}$
Objective: We evaluated a bovine jugular vein graft with a natural trileaflet valve for right ventricular outflow tract reconstruction in a canine study for an entire year. Methods: Heparinized bovine jugular vein grafts with a natural valve cross-linked with a hydrophilic polyepoxy compound of 18 to $20 \mathrm{~mm}$ in internal diameter were implanted in the right ventricularpulmonary arterial position in eight dogs, and the main natural pulmonary artery was ligated. Anticoagulants were not used after implantation. Five grafts were retrieved on day 182 after implantation and the other three grafts on days 196,375 , and 385 , respectively, and were inspected by macroscopic and microscopic observation. Cardiac catheterization, followed by angiography and echocardiography, was done just before graft retrieval. Results: No graft kinking or regurgitation of the valve was observed. Echocardiography showed natural valve motion without thickening of the leaflets. Blood pressure in the conduits ranged from 18/9 to $31 / 4$ $\mathrm{mm} \mathrm{Hg}$, in the right ventricle from $18 / 4$ to $40 / 0 \mathrm{~mm} \mathrm{Hg}$, and the gradient varied from 0 to $14 \mathrm{~mm} \mathrm{Hg}$. The explanted conduits maintained their original shape, softness, and pliability with good coaptation of valves, without calcification or degenerative changes, except for one leaflet with slight deformation. In microscopic observation, endothelial cells lined the luminal surface of the conduit except for the areas adjacent to the valve. Conclusion: The graft worked perfectly as a right ventricular-pulmonary arterial valved conduit without anticoagulant therapy for a long time. (J Thorac Cardiovasc Surg 1997;114:224-33)
$\mathrm{M}$ any kinds of extracardiac conduits have been developed, but the valves of these conduits do not maintain satisfactory hemodynamic function in the low-pressure pulmonary arterial system for very long after implantation. The major problems are the inadequacy of synthetic valves, stenosis caused by degenerative changes of the biologic conduits, or peeling of the pseudointima on the grafts. ${ }^{1-13}$ Other limitations are size, availability, and antithrombogenicity of such bioprostheses for children. Many other problems are present as well, such as the quality of the raw materials and cross-linking of the

From the First Department of Surgery, Yokohama City University School of Medicine, Yokohama, Japan.

Received for publication Dec. 31, 1996; accepted for publication April 16, 1997.

Address for reprints: Yukio Ichikawa, MD, PhD, First Department of Surgery, Yokohama City University School of Medicine, 3-9 Fukuura, Kanazawa-ku, Yokohama 236, Japan.

Copyright $(1997$ by Mosby-Year Book, Inc.

0022-5223/97 $\$ 5.00+0 \quad \mathbf{1 2 / 1 / 8 2 6 6 8}$ bioprostheses in clinics. The ideal graft has to have ideal structure and hemodynamic properties. The cross-linking must provide biocompatibility and hydrophilic properties without cytotoxicity. We must also be able to obtain various sizes of conduits readily at any time. To solve these problems, we developed a conduit using bovine jugular veins, which contain a natural trileaflet valve. These veins with natural valves have the structure peculiar to venous tissue, which makes them adequate to function as a valved conduit in the low-pressure system. To preserve the mechanical properties of the natural tissues and to reduce the immunogenicity of the animal tissue, we treated the graft with a hydrophilic polyepoxy compound (PC) instead of the usual glutaraldehyde. Studies have been conducted comparing the mechanical properties of biologic prostheses cross-linked with PC or glutaraldehyde by measuring their compliance and pliability. An arterial vascular prosthesis cross-linked with $\mathrm{PC}$ showed more pliability than one cross-linked with glutaraldehyde. ${ }^{14}$ The porcine valvular leaflets cross-linked 
with PC were more pliable than their glutaraldehyde counterparts in two-dimensional echocardiographic inspection. Epoxy-treated valves appeared to open more widely than glutaraldehyde-treated valves. Also, less calcium deposition and pannus ingrowth were observed in the epoxy compound valve than in its glutaraldehyde counterpart. ${ }^{15}$

For antithrombogenicity, heparin was immobilized with protamine sulfate on the luminal surface of the graft. In this communication, we report the 1-year results with such a graft in a canine study. The results show that the new right ventricular-pulmonary arterial conduit with a valve naturally functioning in a low-pressure system provides satisfactory hemodynamics and excellent preservation of the venous characteristics.

\section{Materials and methods}

Preparation of the conduit. A fresh bovine jugular vein with a natural valve of 18 to $20 \mathrm{~mm}$ in internal diameter was obtained from a slaughterhouse. It was soaked in distilled water for 1 hour and sonicated at $28 \mathrm{kc}$ for 20 seconds to cause cell destruction. Cell debris and watersoluble proteins were removed by squeezing the vein in distilled water. Thus a natural tissue tube composed of collagen and elastic laminae was obtained (Fig. 1). A 0.7\% protamine sulfate solution, $\mathrm{pH} 5.9$, was impregnated into the luminal surface of the tube by air inflation at a pressure of $30 \mathrm{~mm} \mathrm{Hg}$. During the impregnation, the tube was crimped and cross-linked in a $4 \%$ solution of glycerol polyglycidyl ether polyepoxy compound (PC, Denacol EX-313; Nagase Chemical, Osaka, Japan), pH $9.5 \pm 0.2$ $(0.2 \mathrm{~mol} / \mathrm{L}$ carbonate-bicarbonate buffer $)$, for $45 \pm 3$ hours at $37^{\circ} \mathrm{C}$. After being rinsed with distilled water for more than 24 hours, the tube was soaked in a $1 \%$ heparin solution at $\mathrm{pH} 4.5$ for 5 hours at $45^{\circ} \mathrm{C}$ and then washed again with distilled water for 24 hours. Then it was sterilized in a $4 \%$ solution of PC (Denacol Ex-810; Nagase) for 6 days at $38^{\circ} \mathrm{C}$ and preserved in $70 \%$ ethanol. Before implantation, the graft was squeezed with a dry sponge and immersed in physiologic saline solution three times to remove the ethanol and then soaked in physiologic saline solution for more than 20 minutes.

Implantation of the conduit. Eight young mongrel dogs aged less than 1 year and weighing 7 to $17 \mathrm{~kg}$ were used in this study. The left thoracic cavity was entered though the fourth intercostal space with the dog under general anesthesia with intravenous thiopental sodium $(15 \mathrm{mg} / \mathrm{kg})$ and mechanical ventilation. The pericardium was opened and the main pulmonary artery was exposed. Heparin was administered systemically (100 IU $/ \mathrm{kg}$ ). The initial dose of heparin was calculated at 100 units per kilogram of body weight. The right ventricular outflow tract was partially clamped longitudinally to prevent damage to the coronary artery, and a $3 \mathrm{~cm}$ incision was made. The proximal anastomosis was performed by a continuous over-andover suture with 5-0 polypropylene. The main pulmonary artery was partially clamped longitudinally and incised for

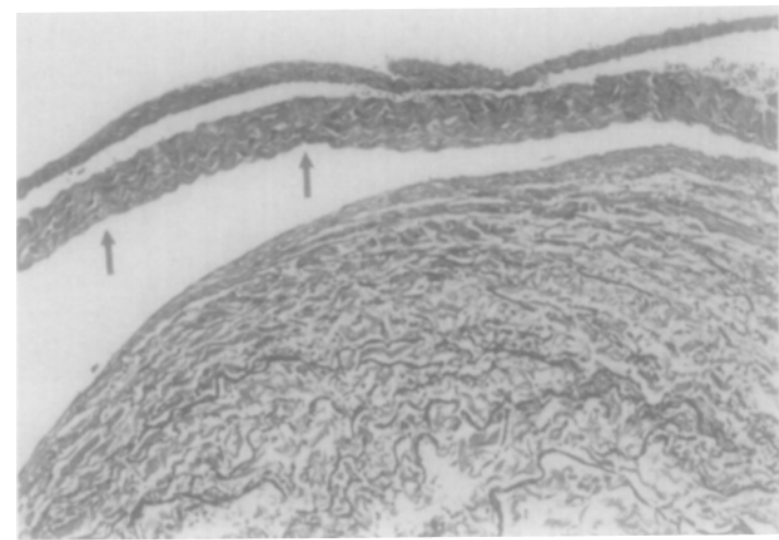

Fig. 1. Microscopic observation of the luminal surface of the prepared graft. The graft was composed of collagen fibers and elastic laminae. Arrowheads indicate leaflet. (Victoria blue staining; original magnification $\times 100$.)

about $2 \mathrm{~cm}$. The distal anastomosis was done with 6-0 polypropylene. After all air had been excluded from inside the graft, the clamps were released, and the main pulmonary artery was ligated at the site between the anastomosis and the pulmonary artery valve. Anticoagulant therapy was not used after the operation.

All animal care was in compliance with the "Principles of Laboratory Animal Care" formulated by the National Society for Medical Research and the "Guide for the Care and Use of Laboratory Animals" prepared by the National Academy of Sciences and published by the National Institutes of Health (NIH publication No. 80-23, revised 1985).

Cardiac catheterization study. A $7 F$ thermodilution catheter was inserted through the left femoral vein under the same general anesthesia as described earlier. The right ventricular-pulmonary arterial pressure gradient across the conduit was measured at 182 days in five dogs and at 196, 376, and 386 days after the operation in the other three dogs. Cardiac catheterization, followed by angiography and echocardiography, was done just before the graft retrieval.

Angiographic study. An angiographic catheter was inserted through the same vessel to allow for catheterization. Conventional right ventricular angiography with cut film was recorded in three dogs at 182 days while about 30 $\mathrm{ml}$ of contrast media was being manually injected into the right ventricle in the left anterior oblique position. Conventional pulmonary artery angiography with motion picture film was also performed in two dogs at 182 and 375 days, respectively, with the same procedure.

Echocardiography. A left thoracotomy was performed through the fourth intercostal space with the animal under general anesthesia. Echocardiography was conducted directly on the graft in two dogs at 182 days and in two dogs at 196 and 385 days, respectively.

Graft retrieval. All grafts were harvested from 182 days to 385 days after the operation with the aid of gencral anesthesia. Five grafts were explanted at $\mathbf{1 8 2}$ days and three grafts at 196,375 , and 385 days after the operation, respectively. 


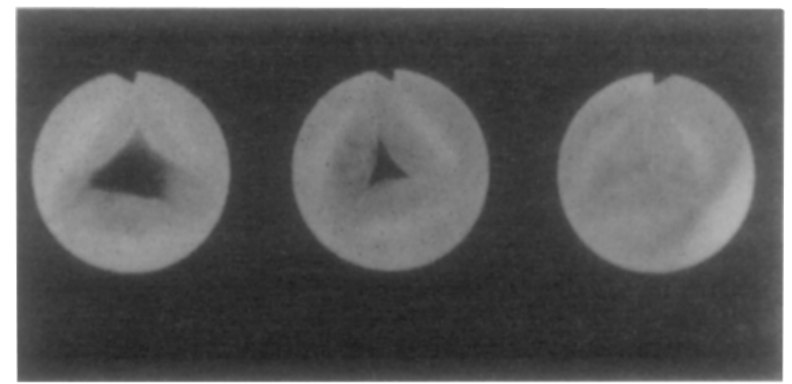

Fig. 2. The natural trileaflet valve of bovine jugular vein graft. Left, Systole: The leaflets opened softly. Center, Midsystole. Right, Diastole: The leaflets closed completely.

Before harvesting, sodium heparin $(100 \mathrm{IU} / \mathrm{kg}$ ) was administered intravenously to prevent clotting. All retrieved grafts were rinsed with saline solution to remove excess intraluminal blood and were inspected macroscopically.

Observations. For light microscopic observation, $3 \mathrm{~mm}$ wide sections of the grafts were cut longitudinally from the right ventricular anastomosis to the pulmonary arterial anastomosis. Each sample was cut into four pieces, and identity marks were placed from the proximal to the distal area to observe the entire length of the graft in sequence. These specimens were fixed with $1 \%$ glutaraldehyde in phosphate buffered solution, $0.2 \mathrm{~mol} / \mathrm{L}, \mathrm{pH} \mathrm{7.4}$, and embedded in a hydrophilic resin (Technovite 7100; Kulzer \& Co. GmbH, Germany). Sections were stained with hematoxylin and eosin, von Kossa stain for the detection of calcification, Papanicolaou's method for the detection of factor VIII of endothelial cells, Victoria blue for collagen, and van Gieson elastin for the detection of elastic fiber.

\section{Results}

Prepared grafts. The bovine jugular vein grafts cross-linked with PC were soft and pliable like native venous tissue, that is, the grafts maintained their original mechanical properties. We could choose a suitable graft from various ones with an internal diameter of from 10 to $30 \mathrm{~mm}$ with two or three natural leaflets. The leaflets were also extremely thin and soft. In saline solution, the leaflets could open and close with a minimum flow of saline solution (Fig. 2). In the present study, grafts of 18 to $20 \mathrm{~mm}$ internal diameter with three leaflets were used. The outer surface of the graft was white and rough with connective tissue velour. The luminal surface was shiny and white (Fig. 3). The graft wall was tough enough to retain sutures.

Implantation of the graft. The graft could be bent to arc on the right ventricular outflow tract because of its elasticity. Handling of the graft, suturability, and coaptation during anastomosis

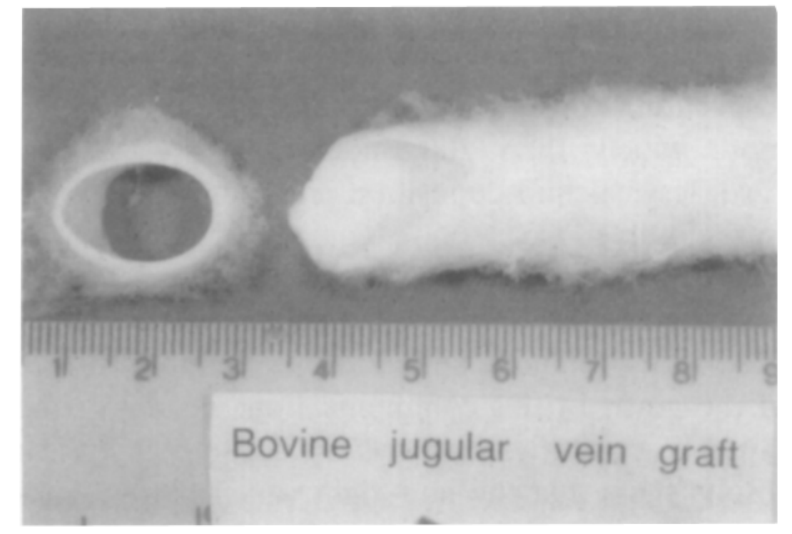

Fig. 3. The bovine jugular vein graft. The outer surface has rough collagen velour.

were not much different from those of native blood vessels. During implantation, blood clotted on the outer surface, but no blood clots adhered to the luminal surface at all. After the clamps were released, no bleeding occurred from the suture line or through the graft wall. After ligation of the original main pulmonary artery, all the blood flowed through the graft, but the right ventricle was not dilated. Opening and closing of the valve were detected by palpation (Fig. 4). Neither kinking, hyperdilatation, nor collapse of the graft was observed. During and after implantation, no undesirable complication developed in any of the animals.

Catheter examination. The results of cardiac catheterization study are shown in Table I. The pressures in the pulmonary artery ranged from 18/9 to $31 / 4 \mathrm{~mm} \mathrm{Hg}$ and in the right ventricle from $18 / 4$ to $78 / 0 \mathrm{~mm} \mathrm{Hg}$. In one $\operatorname{dog}$ at 182 days after the operation ( $\operatorname{dog} 1$ in Table I), the gradient across the conduit was $53 \mathrm{~mm} \mathrm{Hg}$. We found segmented narrowing at the proximal anastomotic site. Except in dog 1 , the pressure gradient across the conduit valve ranged from 0 to $14 \mathrm{~mm} \mathrm{Hg}$ (Fig. 5). The results of two dogs (dogs 4 and 5) were excluded because the ligation of the main pulmonary artery was found to be incomplete in the explanted grafts.

Angiographic examination. Right ventricular angiography showed that all the grafts were patent and had no kinking. The inner surfaces of the conduits were smooth and had no stenosis (Fig. 6). Pulmonary artery cineangiography showed smooth blood flow without regurgitation. No stenosis was detected in the conduits at the valve areas or at the proximal and distal anastomotic sites except at the proximal anastomotic site of dog 1 . 
Table I. Cardiac catheterization data

\begin{tabular}{ccccc}
\hline $\begin{array}{c}\text { Dog } \\
\text { No. }\end{array}$ & $P O D$ & $\begin{array}{c}R V \\
(m m \mathrm{Hg})\end{array}$ & $\begin{array}{c}P A \\
(\mathrm{~mm} \mathrm{Hg})\end{array}$ & $\begin{array}{c}\text { Pressure gradient } \\
(\mathrm{mm} \mathrm{Hg})\end{array}$ \\
\hline 1 & 182 & $78 / 0$ & $25 / 10$ & 53 \\
2 & 182 & $18 / 4$ & $18 / 9$ & 0 \\
3 & 182 & $27 / 3$ & $28 / 10$ & 1 \\
6 & 196 & $40 / 0$ & $31 / 4$ & 9 \\
7 & 375 & $34 / 0$ & $20 / 4$ & 14 \\
8 & 385 & $23 / 2$ & $19 / 7$ & 4 \\
\hline
\end{tabular}

$P O D$, Postoperative day; $R V$, right ventricle; $P A$, pulmonary artery.

Echocardiographic examination. Echocardiography revealed that motion of the valve leaflets in each conduit was natural in the low-pressure pulmonary arterial system for a long period. The leaflets did not show thickening or high echoic lesions, which would indicate calcification of the valve (Fig. 7). Blood flow did not regurgitate through the valve in any of the conduits, and none of the graft walls became dilated.

Retrieved grafts from animals. All the grafts were patent, maintained extensibility, elasticity, and softness without hard calcified lesions, and had no dilatation at the time of their harvesting. The luminal surfaces were extremely smooth, without degenerative changes. No graft stenosis was observed as a result of intimal hyperplasia. The luminal surfaces from the anastomotic sites to the areas near the valves were white and glistening without thrombus deposition in all the grafts (Fig. 8). However, in dog 1 we found scar formation in the right ventricular muscle at the anastomotic site, resulted in narrowing of the conduit at the proximal end. Small pieces of fresh thrombus were present on 16 of 24 cusps, and one cusp was slightly deformed at 182 days.

Microscopic observations. The explanted graft maintained its own structure, elastic fibers, and collagen fibers (Fig. 9). There was no migration of giant cells, macrophages, or lymphocytes caused by foreign body reactions, and there were no degenerative changes and no calcification in the graft wall. The specimens of the graft with von Kossa staining showed no calcification (Fig. 10). Neointima formation with endothelium-like cell lining was observed on the luminal surface in all the conduits from the anastomotic sites to the areas near the valves (Fig. 11). These cells were positive for factor VIII with Papanicolaou staining, suggesting that they were endothelial cells. On the valves and the adjacent areas, however, no endothelial cells were present. Small fresh thrombus adhered to some cusps without fibroblast

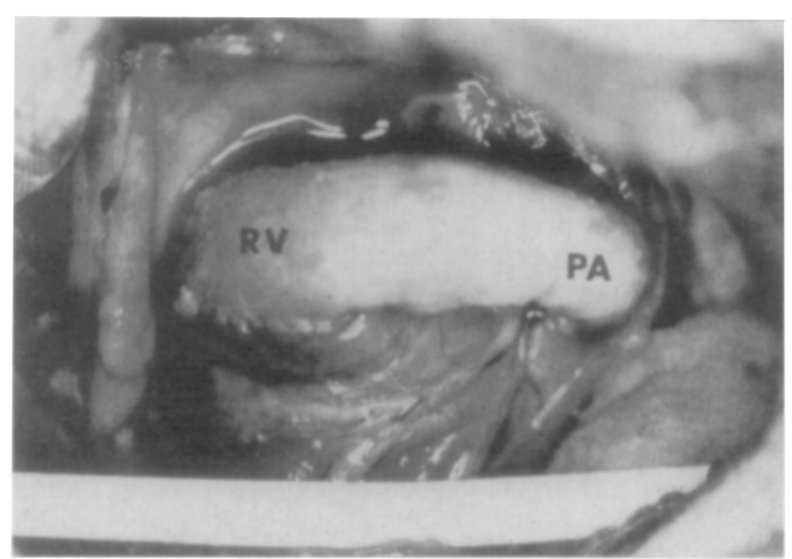

Fig. 4. The right ventricular-pulmonary arterial ( $R V-P A)$ bypass with the new graft. The outer wall of the valve is slightly ballooned.

migration. In the valve with slight deformation in case 1 , we observed fibrin deposition with erythrocytes and fibroblast migration. At both proximal and distal anastomotic sites, no intimal hyperplasia was present.

\section{Discussion}

The grafts made of bovine jugular vein with natural venous valves maintained natural valve function in a low-pressure area of the pulmonary arterial system for an entire 1-year observation period. No significant dilated area was present in any of the retrieved conduits. This finding was consistent with a short-term right ventricular angiographic observation in a preliminary study. ${ }^{16}$ The pressure gradient across the conduit valve ranged from 0 to $14 \mathrm{~mm} \mathrm{Hg}$, which was a satisfactory value when compared with the mean gradient across the conduit $(22.8 \mathrm{~mm} \mathrm{Hg})$ at completion of the operation with an extracardiac conduit in clinics. ${ }^{11}$ In one $\operatorname{dog}(\operatorname{dog} 1)$, scar formation was noted in the right ventricular muscle at the anastomotic site. This finding was consistent with the results of the angiographic examination. The high pressure gradient in this case was considered to be caused by this scar formation.

Although we did not use any anticoagulants after the graft implantation, thrombus adhesion at the leaflets was minimal, and these thrombi were extremely fresh without organization. Therefore the thrombi could have been created during the catheterization just before the graft retrieval. Endothelialization of the graft surface was also observed without intimal hyperplasia or degenerative changes such as calcification. All this evidence indicates that 


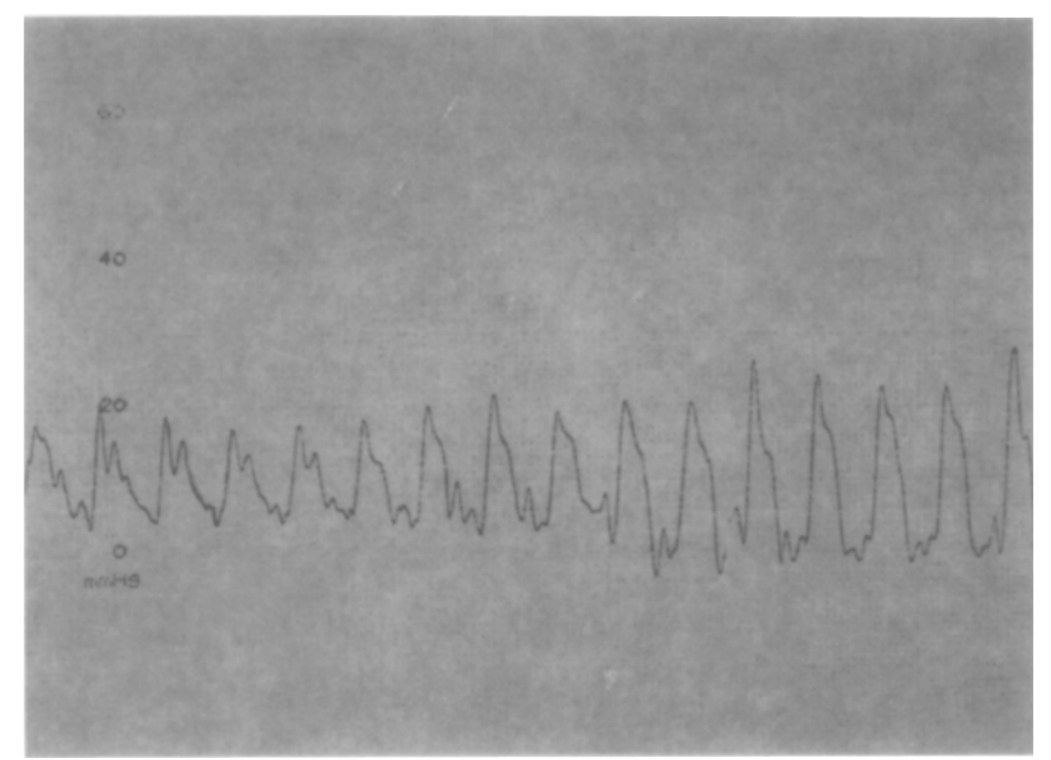

Fig. 5. The pressure gradient across the conduit valve at $\mathbf{3 8 5}$ days after the operation.

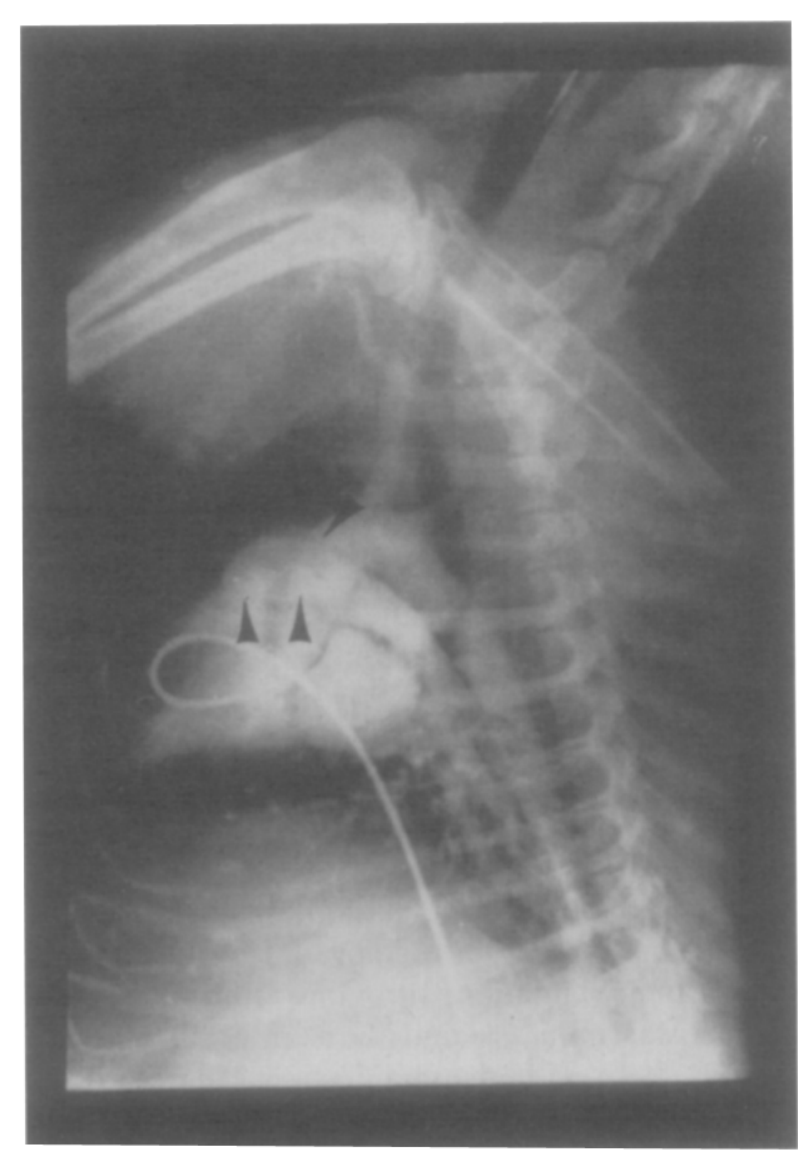

Fig. 6. Right ventriculogram 182 days after the operation. The conduit was patent, unkinked, and undilated. Arrowheads indicate the conduit. the graft worked perfectly as a right ventricularpulmonary arterial valved conduit for a long period of time and should be considered for clinical use.

In the current experiment, no control conduit was adopted because no suitable standard conduit for clinical use was available. Therefore we will discuss our results with the results reported in various references. ${ }^{1-13}$ Total surgical repair of congenital heart lesions with pulmonary arterial-right ventricular discontinuity was first accomplished with an aortic homograft in a patient with tetralogy of Fallot and pulmonary atresia. ${ }^{17}$ Many kinds of conduits have been reported for right ventricular outflow tract reconstruction, but no conduits have maintained functional valves without degenerative changes or calcification without anticoagulant therapy. ${ }^{1-13}$

Recently, success has been reported with cryopreserved allografts. ${ }^{18,19}$ These grafts functioned for more than 10 years, which was a tremendous result compared with our 1-year experiment. Unfortunately, almost all showed valvular regurgitation. Selection of the size of the grafts was also discussed, and immunogenic problems as the pathogenesis of valve allograft failure were also pointed out. There are limitations to homografts, such as ready availability and size of the graft. On the other hand, we could choose from grafts with an internal diameter of from 10 to $30 \mathrm{~mm}$. There were no limitations of availability and size of the graft in our bioprostheses. 

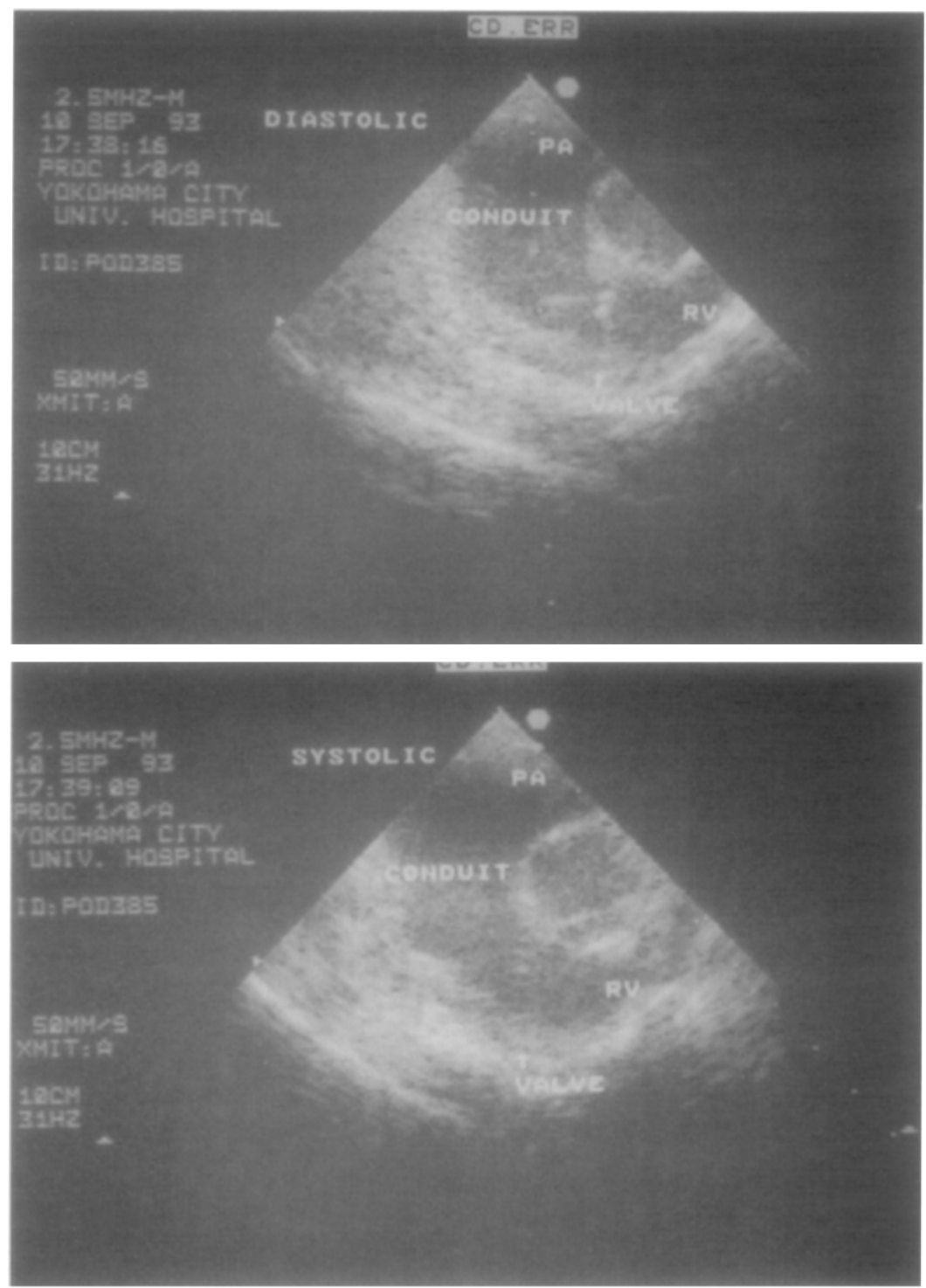

Fig. 7. Echocardiograms of the graft 385 days after the operation. $R V$, Right ventricle; $P A$, pulmonary artery. Valvular swaying is maintained satisfactorily.

Biologic valves made of porcine aortic valves have been used and are expected to maintain their function continuously. Their leaflets are, however, too rigid to work in the low-pressure system, because these grafts originate from aortic valves, not from pulmonary valves. It has been reported that the ratio of thickness of the media of the pulmonary trunk to that of the aorta was approximately $0.6,{ }^{20}$ that the amount of pulmonary elastic tissue per unit of medial surface area in a histologic section was only $50 \%$ to $60 \%$ of that in the aorta, ${ }^{20}$ and that the total calcium content per gram of tissue in the pulmonary media was on an average less than half of that in the aortic counterpart. ${ }^{21}$ Early calcification and stenosis of glutaraldehyde-treated porcine valves in children have been observed., 13

Another problem is the cross-linking method. The grafts previously reported have been cross-linked with glutaraldehyde, which makes biologic materials stiff and hydrophobic. ${ }^{22,23}$ Cytotoxicity of residual glutaraldehyde released from the graft long after implantation can also induce another problem, foreign body reaction. ${ }^{24}$ Host cells cannot migrate onto the cytotoxic area. ${ }^{25}$ Therefore no endothelial cell lining can be hoped for in the glutaraldehydetreated grafts. 


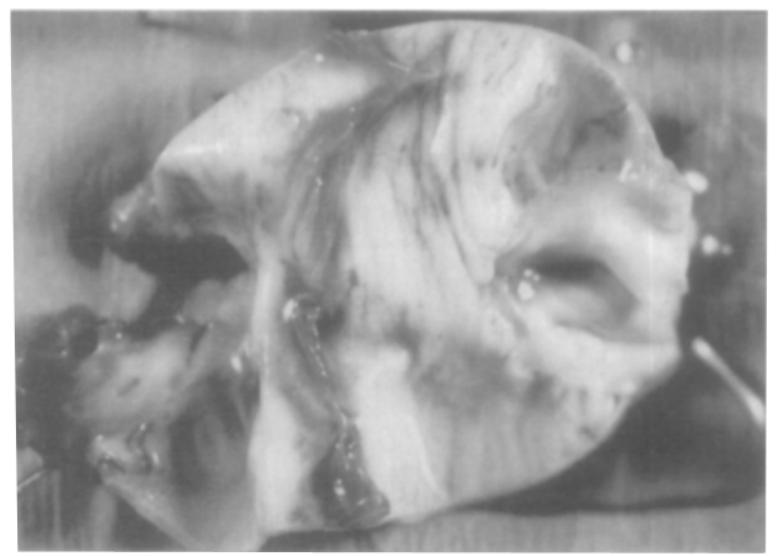

Fig. 8. The inner surface of the explanted graft 196 days after the operation. No intimal hyperplasia and no thrombus is apparent on the luminal surface of the graft except for a small thrombus on the valve.

Previously, cardiac wall substitute composed of collagen-coated ultrafine polyester mesh crosslinked by a hydrophilic polyepoxy compound (CUFP) or glutaraldehyde-treated equine pericardium was evaluated for right ventricular outflow tract implantation in dogs. There was endothelialization in the CUFP with fibroblasts and smooth muscle-like cells, but no endothelialization was seen in the glutaraldehyde-treated graft without fibroblasts. ${ }^{26}$ The glutaraldehyde treatment completely alters the original properties of the grafts.

To overcome these problems, we used three special technologies for the new valved conduit. First, as the raw material for the graft with valves, we used the bovine jugular vein, which has natural valves with adequate shape, structure, function, and mechanical properties to work in the low-pressure system without thrombus formation. These remarkable characteristics cannot be created by any one or combination of the various synthetic materials by means of currently available technology. Today's technology has produced various successful medical devices, but as raw materials for artificial organs, natural tissues and organs have still attractive properties both morphologically and functionally. The natural vein with venous valves is a typical case. If we can preserve these remarkable properties of natural tissues by some kind of chemical modification, we can produce ideal artificial organs in various fields.

Second, we used PC instead of glutaraldehyde for chemical cross-linking. PC cross-linking has been used for small-diameter vascular prostheses of bio-

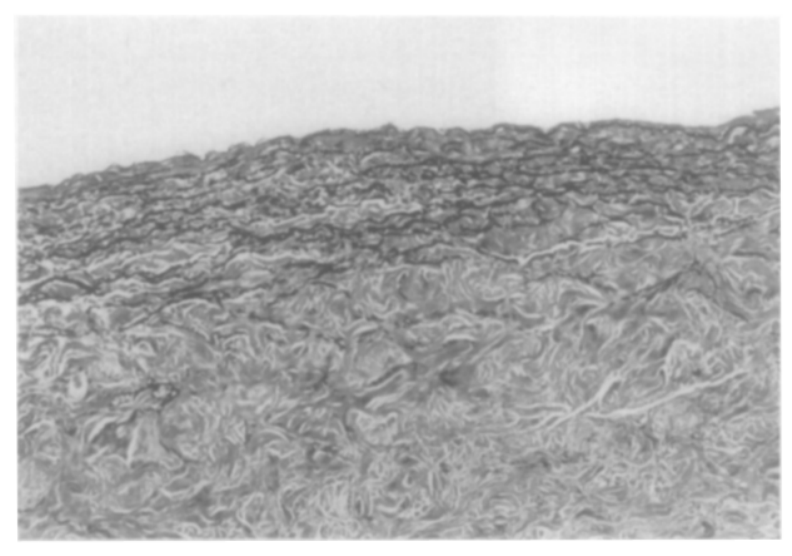

Fig. 9. Microscopic observation of the luminal surface of the graft 385 days after the operation. (Van Gieson elastin stain; original magnification $\times 100$.)

logic origin to preserve natural tissue elasticity and pliability. ${ }^{27,30} \mathrm{PC}$ contains ether bounds in its molecule. The ether bound is a free joint, and it makes the cross-linked graft soft and flexible. PC also contains hydroxyl groups in its molecule, which give the materials hydrophilicity. On the other hand, glutaraldehyde contains a continuous five-carbon chain, which is rigid and hydrophobic, and makes the cross-linked materials stiff and hydrophobic. Another advantage of $\mathrm{PC}$ is its low cytotoxicity compared with that of glutaraldehyde, ${ }^{25}$ and materials cross-linked with PC do not show foreign body reaction after implantation. ${ }^{29,31}$ Host cells can proliferate on the graft surface and migrate into the graft framework with the hydrophilicity and low cytotoxicity offered by PC. Consequently, PC crosslinking can provide a suitable environment for host cell migration, resulting in endothelial cell lining on the graft surface. Microscopic observation in the current study indicated that the endothelial cells migrated 1 to $2 \mathrm{~cm}$ away from the suture lines to near the leaflets, but no endothelialization was noted on the leaflets. Because endothelial cell division is limited by cell aging, endothelial lining to cover the entire surface of the graft is difficult. ${ }^{32,33}$ In the present experiment, the valves maintained their original mechanical properties after the PC cross-linking.

In general, biologic materials that contain collagen are thrombogenic, because collagen molecules have many amino groups that are positively charged and can accumulate negatively charged platelets. ${ }^{34,35}$ These amino groups, however, are used for the cross-linking reaction, and carboxyl groups in 


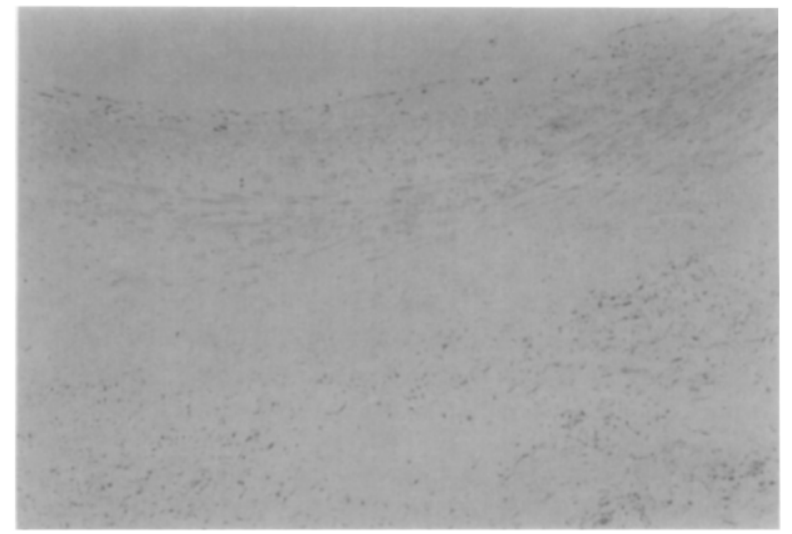

Fig. 10. Microscopic observation of the luminal surface of the graft 385 days after the operation. (von Kossa staining; original magnification $\times 100$.)

the collagen molecules become relatively dominant. Therefore the materials become negatively charged and become less thrombogenic, ${ }^{36}$ since platelets, which have a negative charge, show repulsion toward the same charge. Moreover, biologic materials cross-linked with PC become hydrophilic, because PC contains hydroxyl groups. In general, hydrophilic substances in wet conditions are surrounded with water, and water does not initiate either platelet aggregation or fibrin precipitation. Therefore, after cross-linking with $\mathrm{PC}$, the biologic materials acquire nonthrombogenic properties.

Third, we used a special heparinization method for powerful antithrombogenicity. Heparin was bound in the luminal surface of the graft in which protamine sulfate was impregnated in advance and bound covalently during the PC cross-linking. Protamine can bind heparin ionically and release it slowly after implantation. During the heparin release, fibrin cannot precipitate on the graft surface, but endothelial cells can migrate and proliferate on it. ${ }^{27}$ Therefore, after heparin is gone, endothelial cells can prevent thrombus formation on the graft surface. Even in small-diameter grafts, the graft maintained its patency with the heparinization technology in the aorta-coronary bypass for the entire 1-year observation period. ${ }^{29,31,37}$ The antithrombogenicity induced by the slow release of heparin proved to be effective in the pulmonary arterial system, and the graft worked perfectly without anticoagulant therapy. This is a great advantage when the graft is used in infants and young children in whom anticoagulant treatments cannot be used after implantation.

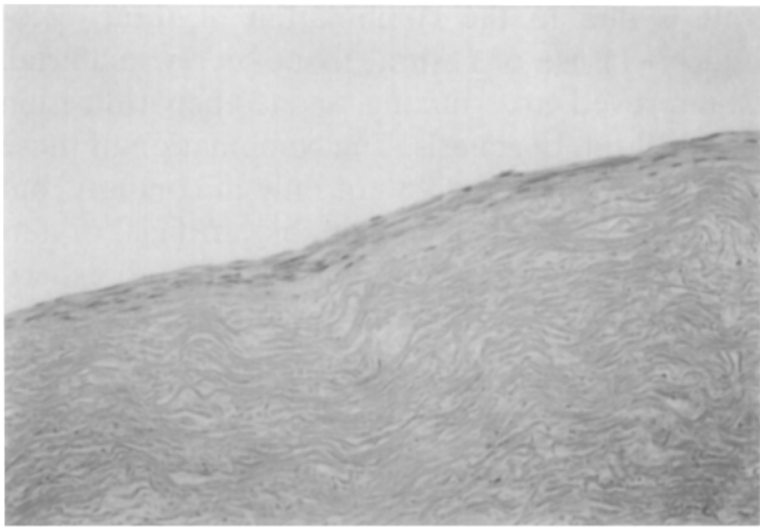

Fig. 11. Microscopic observation of the luminal surface of the graft 182 days after the operation. The graft shows endothelium-like cells. (Hematoxylin and eosin staining; original magnification $\times 100$.)

Another concern related to biologic materials for infants and young children is degenerative changes such as calcification. Collagen materials cross-linked with PC have proved to induce less calcification than those cross-linked with glutaraldehyde. In growing rats, the calcification rate of biologic valves crosslinked with PC was less than $1 \%$ compared with those cross-linked with glutaraldehyde. ${ }^{38}$ Previous articles on PC-cross-linked aortic valves implanted in both the systemic and the pulmonary arterial systems did not report any calcification. ${ }^{38}$ In the present experiments, we did not use growing animals, but young dogs less than 1 year old, and the graft showed no calcification during the observation period. We can expect a similar result in human beings as well.

Peeling of the neointima has been reported as a complication of right ventricular-pulmonary arterial conduits. ${ }^{9,12}$ Our hypothesis is that the peeling is caused structurally by intimal hyperplasia associated with poor anchoring of the neointima on the graft surface and biologically poor cell affinity of the neointima to the graft surface. Highly porous Dacron fabric grafts do not show peeling. ${ }^{39,40}$ In high cell-affinity grafts such as PC-cross-linked biologic materials, neointimae on the graft surfaces are thin and biologically stable and do not become detached from the luminal surfaces. Our grafts had a thin neointima, lined with endothelial cells without intimal hyperplasia, which adhered stably to the graft. We believe that the probability of peeling in our grafts is very low.

In summary, we believe that the success of our 
graft is due to the combination of three techniques: (1) use of natural tissue as raw material, (2) improved cross-linking, and (3) heparinization for antithrombogenesis. The combination of these techniques is applicable not only in conduits, but also in various other implantable artificial organs in general. We are now continuing our experiments to make results with these grafts comparable with the allograft results obtained with 10 -year observation.

\section{REFERENCES}

1. Gundry SR, Razzouk AJ, Boskind JF, Bansal R, Bailey LL. Fate of the pericardial monocusp pulmonary valve for right ventricular outflow tract reconstruction: early function, late failure without obstruction. J Thorac Cardiovasc Surg 1994; 107:908-13.

2. Norwood WI, Freed MD, Rocchini AP, Bernhard WF, Castaneda AR. Experience with valved conduits for repair of congenital cardiac lesions. Ann Thorac Surg 1977;24: 223-32.

3. Saravalli OA, Somerville J, Jefferson KE. Calcification of aortic homografts used for reconstruction of the right ventricular outflow tract. J Thorac Cardiovasc Surg 1980;80:90220.

4. Agarwal KC, Edwards WD, Feldt RH, Danielson GK, Puga FJ, McGoon DC. Pathogenesis of nonobstructive fibrous peels in right-sided porcine-valved extracardiac conduits. J Thorac Cardiovase Surg 1982;83:584-9.

5. Gabbay S, Bortolotti U, Factor S, Shore DF, Frater RWM. Calcification of implanted xenograft pericardium: influence of site and function. $\mathbf{J}$ Thorac Cardiovasc Surg 1984;87:782-7.

6. Stewart S, Manning J, Alexson C, Harris P. The Hancock external valved conduit: a dichotomy between late clinical results and late cardiac catheterization findings. J Thorac Cardiovasc Surg 1983;86:562-9.

7. Agarwal KC, Edwards WD, Feldt RH, Danielson GK, Puga FJ, McGoon DC. Clinicopathological correlates of obstructed right-sided porcine-valved extracardiac conduits. J Thorac Cardiovasc Surg 1981;81:591-601.

8. Bowman FO Jr, Hancock WD, Malm JR. A valve-containing Dacron prosthesis. Arch Surg 1973;107:724-8.

9. Jonas RA, Freed MD, Mayer JE Jr, Castaneda AR. Longterm follow-up of patients with synthetic right heart conduits. Circulation 1985;72:77-83.

10. Schaff HV, DiDonato RM, Danielson GK, et al. Reoperation for obstructed pulmonary ventricle-pulmonary artery conduits. J Thorac Cardiovasc Surg 1984;88:334-43.

11. Ciaravella JM Jr, McGoon DC, Danielson GK, Wallace RB, Mair DD, Ilstrup DM. Experience with the extracardiac conduit. J Thorac Cardiovasc Surg 1979;78:920-30.

12. McGoon DC, Danielson GK, Puga FJ, Ritter DG, Mair DD, Ilstrup DM. Late results after extracardiac conduit repair for congenital cardiac defects. Am J Cardiol 1982; 49:1741-9.

13. Cipriano PR, Billingham ME, Oyer PE, Kutsche LM, Stinson EB. Calcification of porcine prosthetic heart valves: a radiographic and light microscopic study. Circulation 1982;66: 1100-4.
14. Tu R, Wang E, Hata C, Shen SH, Lin D, Quijano RC. A compliance biological vascular prosthesis. Int J Artif Organs $1993 ; 16: 141-5$.

15. Sung HW, Tu R, Shen SH, et al. A newly developed porcine heart valve bioprosthesis fixed with an epoxy compound: an experimental evaluation. ASAIO J 1994;40:192-8.

16. Ichikawa Y.A new RV-PA conduit with a natural valve made of bovine jugular vein. ASAIO J 1992;38:266-70.

17. Ross DN, Somerville J. Correction of pulmonary atresia with a homograft aortic valve. Lancet 1966;2:1446-7.

18. Clarke DR, Bishop DA. Ten year experience with pulmonary allografts in children. J Heart Valve Dis 1995;4:38491.

19. Tam RK, Tolan MJ, Zamvar VY, et al. Use of larger sized aortic homograft conduits in right ventricular outflow tract reconstruction. J Heart Valve Dis 1995;4:660-4.

20. Plank L, James J, Wagenvoort CA. Caliber and elastin content of the pulmonary trunk. Arch Pathol Exp Med 1979;104:238-45.

21. Livi U, Abdulla AK, Parker R, Olsen EJ, Ross DN. Viability and morphology of aortic and pulmonary homografts. J Thorac Cardiovasc Surg 1987;93:755-60.

22. Levy RJ, Schoen FJ, Levy JT, et al. Biologic determinants of dystrophic calcification and osteocalcin deposition in glutaraldehyde-preserved porcine aortic valve leaflets implanted subcutaneously in rats. Am J Pathol 1983;113:14355.

23. Gott JP, Chih P, Dorsey LMA, et al. Calcification of porcine valves: a successful new method of antimineralization. Ann Thorac Surg 1992;53:207-16.

24. Wiebe D, Megerman J, L'Italien GJ, Abbott WM. Glutaraldehyde release from vascular prostheses of biologic origin. Surgery 1988;104:26-33.

25. Speer DP, Chvapil M, Eskelson CD, Ulreich J. Biological effects of residual glutaraldehyde in glutaraldehyde-tanned collagen biomaterials. J Biomed Mater Res 1980;14:75364.

26. Okoshi Y, Noishiki Y, Tomizawa Y, Morishima M, Terada $\mathrm{R}$, Koyanagi H. Long-term results of a new antithrombogenic cardiac wall substitute. ASAIO Trans 1989;35:391-5.

27. Noishiki Y, Miyata T. Successful animal study of small caliber heparin-protamine-collagen vascular grafts. ASAIO Trans 1985;31:102-6.

28. Noishiki Y, Miyata T, Kodaira K. Development of a small caliber vascular graft by a new crosslinking method incorporating slow heparin release collagen and natural tissue compliance. ASAIO Trans 1986;32:114-9.

29. Nojiri C, Noishiki Y, Koyanagi H. Aorta-coronary bypass grafting with heparinized vascular grafts in dogs: a preliminary study. J Thorac Cardiovasc Surg 1987;93:867-77.

30. Tomizawa Y, Noishiki Y, Okoshi T, Miyata T, Koyanagi $H$. Aortocoronary bypass grafting with hydrophilic small caliber vascular grafts. ASAIO Trans 1989;35:199-202.

31. Noishiki Y, Miyata T, Nojiri C, Koyanagi H. A small-caliber vascular graft for aortocoronary artery graft with temporarily artificial and permanently natural antithrombogenicity and natural vessel compliance. Artif Heart 1987 Aug 2;13-14,7584.

32. Hoshi H, McKeehan W. Isolation, growth requirement, cloning, prostacycline production and life-span of human adult endothelial cells in low serum culture medium. In Vitro Cell Dev Biol 1986;22:51-6. 
33. Golden PB, Sussman I, Hatchet VB. Long-term culture of human endothelial cells. In Vitro Cell Dev Biol 1983;19:661-71.

34. Wang CL, Miyata T, Schlear S, Weksler B, Rubin AL, Stenzel KH. Collagen and glomerular membrane effects on platelets. ASAIO Trans 1975;21:422-6.

35. Wang CL, Miyata T, Weksler B, Rubin AL, Stenzel KH. Collagen-induced platelet aggregation and release. II. Critical size and structual requirements of collagen. Blochem Biophys Acta 1978;544:568-77.

36. Miyata T, Schwartz A, Wang CL, Rubin AL, Stenzel KH. Deposition of platelets and fibrin on chemically modified collagen hollow fibers. ASAIO Trans 1976;22:1-7.
37. Tomizawa Y, Moon MR, DeAnda A, Castro LJ, Kosek J, Miller C. Coronary bypass grafting with biological grafts in a canine model. Circulation 1994;90:160-6.

38. Okoshi Y, Noishiki Y, Tomozawa Y, et al. A new bioprosthetic cardiac valve with reduced calcification. ASAIO Trans 1990;36:411-4.

39. Wesolowski SA. Evaluation of tissue and prosthetic vascular grafts. Springfield (IL): Charles C Thomas; 1962. p. $1-110$.

40. Wesolowski SA. Porosity, primary determinant of ultimate fate of synthetic vascular grafts. Surgery 1961;59:9196.

\section{Bound volumes available to subscribers}

Bound volumes of The Journal of Thoracic and Cardiovascular Surgery are available to subscribers (only) for the 1997 issues from the Publisher, at a cost of $\$ 110.50$ for domestic, $\$ 139.64$ for Canadian, and $\$ 130.50$ for international subscribers for Vol. 113 (January-June) and Vol. 114 (July-December). Shipping charges are included. Each bound volume contains a subject and author index and all advertising is removed. Copies are shipped within 60 days after publication of the last issue of the volume. The binding is durable buckram with the Journal name, volume number, and year stamped in gold on the spine. Payment must accompany all orders. Contact Mosby-Year Book, Inc., Subscription Services, 11830 Westline Industrial Drive, St. Louis, Missouri 63146-3318, USA; phone 800-453-4351 or 314-453-4351.

Subscriptions must be in force to qualify. Bound volumes are not available in place of a regular Journal subseription. 